\title{
Cytogenetic characterization of Eurysternus caribaeus (Coleoptera: Scarabaeidae): evidence of sex-autosome fusion and diploid number reduction prior to species dispersion
}

\author{
AMANDA PAULINO DE ARCANJO ${ }^{1}$, DIOGO CAVALCANTI CABRAL-DE-MELLO ${ }^{2}$, \\ ANA EMÍLIA BARROS E SILVA ${ }^{3}$ and RITA DE CÁSSIA DE MOURA ${ }^{1 *}$ \\ ${ }^{1}$ Departamento de Biologia, Instituto de Ciências Biológicas, UPE-Universidade de Pernambuco, 50100-130, Recife, Brazil \\ ${ }^{2}$ Departamento de Morfologia, Instituto de Biociências, UNESP-Universidade Estadual Paulista, \\ 18618-000, Botucatu, Brazil \\ ${ }^{3}$ Departamento de Botânica, Centro de Ciências Biológicas, UFPE-Universidade Federal de Pernambuco, \\ 50670-420, Recife, Brazil
}

\begin{abstract}
Mitotic and meiotic chromosomes of several populations of Eurysternus caribaeus (Coleoptera: Scarabaeidae) were analysed through conventional staining, C-banding, base-specific fluorochromes, silver nitrate staining and fluorescent in situ hybridization (FISH). All specimens showed $2 n=8$ in their karyotypes, with a neo-XY sex system ( $\mathrm{Y}$ is a submetacentric and $\mathrm{X}$ a metacentric) and three pairs of submetacentric autosomes. The analysis of constitutive heterochromatin $(\mathrm{CH})$ revealed small blocks located in the centromeric region of all chromosomes which do not present positive staining under the fluorochromes $\mathrm{CMA}_{3}$ and DAPI. Silver nitrate staining revealed that the nucleolar organizer region (NORs) is associated with the sex chromosomes. The FISH technique revealed that rDNA sites in the $\mathrm{X}$ and $\mathrm{Y}$ are different in size. Data from different populations indicate that the diploid number reduction $(2 n=8)$ observed in E. caribaeus is established and presumably has preceded the dispersion of this species. Moreover, this reduction occasioned the translocation of rDNA sites to the sex chromosomes, $\mathrm{X}$ and Y, an uncommon pattern in Scarabaeidae that was observed for the first time by the FISH in this work.
\end{abstract}

[Arcanjo A. P., Cabral-de-Mello D. C., Silva A. E. B. and Moura R. C. 2009 Cytogenetic characterization of Eurysternus caribaeus (Coleoptera: Scarabaeidae): evidence of sex-autosome fusion and diploid number reduction prior to species dispersion. J. Genet. 88, $177-182]$

\section{Introduction}

The cosmopolitan beetle family Scarabaeidae comprises approximately 2000 genera and 25,000 species. In Neotropical region, about 4706 species have been recorded, and 1777 species were identified in Brazil (Costa 2000). Some of their representatives show important functions as pollinators of plants, organic matter recyclers and biologic controllers of agricultural plagues, acting moreover as indicators for the analysis of biodiversity in tropical forest (Halffter and Favila 1993).

Despite the large number of species, there are few studies about the chromosomal diversity of Scarabaeidae

\footnotetext{
*For correspondence. E-mail: rita_upe@yahoo.com.br.
}

representatives and approximately, only 390 species (1.57\%) have been analysed, predominantly using conventional staining. This family shows conserved karyotypes with more than $50 \%$ of the species presenting the diploid number $2 n=20$, $\mathrm{Xy}_{\mathrm{p}}$ sex mechanism and biarmed chromosomes. This condition has been considered primitive to this group and also to the whole order Coleoptera (Smith and Virkki 1978; Yadav et al. 1979; Martins 1994; Moura et al. 2003; Bione et al. 2005a,b; Cabral-de-Mello et al. 2008). However, variations of diploid number, sex mechanism and, to a lesser extent, chromosomal morphology have also been recorded. The species Eurysternus caribaeus has the lowest $(2 n=8)$, while Autoserica assamensis the highest diploid number for the family $(2 n=30)$ (Yadav et al. 1979; Cabral-de-Mello et al. 2007). The family presents seven sex mechanisms

Keywords. chromosome rearrangements; FISH; heterochromatin; meiosis; NORs. 
(XY, Xy, $\mathrm{XY}_{\mathrm{p}}, \mathrm{Xy}_{\mathrm{p}}, \mathrm{Xy}_{\mathrm{r}}, \mathrm{XO}$ and neo-XY) with variations in the chromosomal morphology in some species (Yadav et al. 1979; Moura et al. 2003; Bione et al. 2005a,b; Cabral-deMello et al. 2007; Dutrillaux et al. 2007).

In some Coleopteran families, wide karyotypic structure variation has been reported, as described for Buprestidae $(2 n=12$ to $2 n=46)$ and Elateridae $(2 n=4$ to $2 n=23)$, whereas karyotypic conservation has been observed in others, such as Lampyridae $(2 n=19$, XO), and Cantharidae $(2 n=13, \mathrm{XO})$ (Smith and Virkki 1978; Machado et al. 2001; Karagyan et al. 2004; Dias et al. 2007; Schneider et al. 2007a). In the insect class, as a whole, there are groups that present modal and conserved diploid number, i.e. acridid grasshopper (Orthoptera), Libellulidae (Odonata), and groups less conserved showing variation in number of autosomes and/or sex chromosomes, for example in Phaneropterinae (Tettigoniidae, Orthoptera) and Reduviidae (Heteroptera) (Hewitt 1979; Mola et al. 1999; Ferreira and Mesa 2007; Poggio et al. 2007).

About 70 Scarabaeidae species have been studied using differential or molecular cytogenetic techniques, such as Cbanding, base-specific fluorochromes, silver nitrate staining or fluorescence in situ hybridization (FISH) (Moura et al. 2003; Wilson and Angus 2004, 2005, 2006; Bione et al. 2005a,b; Angus et al. 2007; Dutrillaux et al. 2007). The constitutive heterochromatin $(\mathrm{CH})$ in this family is predominantly located in the pericentric region of the chromosomes and this genomic component shows wide heterogeneity regarding AT-richness and GC-richness. Moreover, species with telomeric, interstitial $\mathrm{CH}$ and diphasic chromosomes have been described in this family (Colomba et al. 1996, 2000, 2006; Moura et al. 2003; Bione et al. 2005a; Angus et al. 2007; Macaisne et al. 2006). The nucleolar organizer regions (NORs) are predominantly located in a single autosomal pair or in the X chromosome. However, some species show more than one rDNA site clustered in different chromosome pairs (Moura et al. 2003; Bione et al. 2005a,b; Macaisne et al. 2006).

Previous cytogenetic studies have been carried out in one of the populations of E. caribaeus and showed the presence of the smallest diploid number observed in the superfamily Scarabaeoidea (Cabral-de-Mello et al. 2007). In the present study, conventional staining, C-banding, silver nitrate staining, base-specific fluorochromes $\mathrm{CMA}_{3}$ and DAPI, and FISH were used to characterize the karyotype of several populations of E. caribaeus. The results obtained indicate that the chromosome structure has remained conserved during the dispersion of the species and fusion of autosomal and sexual elements had occurred in the generation of the karyotype of E. caribaeus.

\section{Materials and methods}

Mitotic and meiotic chromosomes of 22 male specimens of E. caribaeus were analysed. The animals were col- lected from forest areas of Pernambuco state (Brazil), Paudalho (11 specimens) ( $7^{\circ} 57^{\prime} 56^{\prime \prime} \mathrm{S}$ and $\left.35^{\circ} 00^{\prime} 07^{\prime \prime} \mathrm{W}\right)$, Igarassu (three specimens) $\left(7^{\circ} 48^{\prime} 37^{\prime \prime} \mathrm{S}\right.$ and $\left.34^{\circ} 27^{\prime} 25^{\prime \prime} \mathrm{W}\right)$, and Caruaru (five specimens) $\left(8^{\circ} 42^{\prime} \mathrm{S}\right.$ and $\left.35^{\circ} 15^{\prime} \mathrm{W}\right)$. Further, three specimens from botanical garden of Santa Cruz de la Sierra city $\left(17^{\circ} 47^{\prime} 21^{\prime \prime} \mathrm{S}\right.$ and $\left.63^{\circ} 11^{\prime} 48^{\prime \prime} \mathrm{W}\right)$, Bolivia, were analysed.

The insects were anesthetized with ether, and their testicular follicles were dissected and fixed in Carnoy (3:1, ethanol: acetic acid). Chromosome preparations were obtained by the classic testicular follicles crushing technique. For conventional staining 2\% lacto-acetic orcein was used. The C-banding was performed according to Sumner (1972), with modifications. The material was incubated with $0.2 \mathrm{~N}$ $\mathrm{HCl}$, followed by treatment with $5 \%$ barium hydroxide and $2 \times \mathrm{SSC}$ at $60^{\circ} \mathrm{C}$. Triple combination of the fluorochromes $\mathrm{CMA}_{3} / \mathrm{DA} / \mathrm{DAPI}$ and silver staining were performed using the protocols of Schweizer (1976) and Rufas et al. (1987) respectively, and FISH followed the procedure of Moscone et al. (1996), using a probe of 45S rDNA isolated from Arabidopsis thaliana. The images were captured in Leica DM LB microscope (Leica Microsystems, Wetzlar, Germany) and the figures were organized using the Corel Photo-Paint 12 software (Corel corporation 2003, Ottawa, Canada).

\section{Results}

\section{Conventional staining}

The 22 analysed individuals of $E$. caribaeus from the different populations showed diploid number $2 n=8$ and a neo-XY sex chromosome mechanism (meioformule $3 \mathrm{II}+$ neo-XY). The karyotype of this species is symmetric with gradual reduction in size. The autosomes and the Y showed submetacentric morphology and the $\mathrm{X}$ is a metacentric element (figure $1, \mathrm{a} \& \mathrm{~b})$

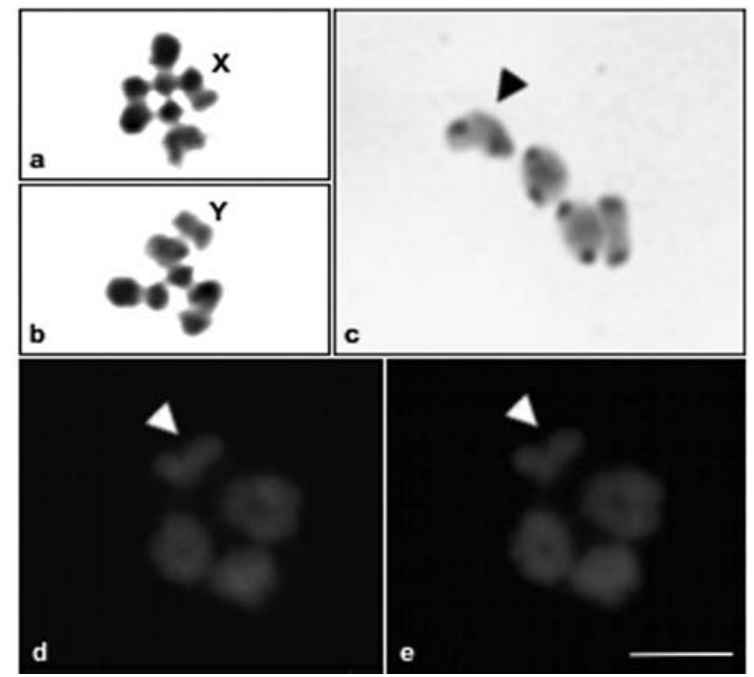

Figure 1. Meiotic chromosomes of E. caribaeus. (a\&b) Conventional staining of metaphases II, (c) C-banding, (d) $\mathrm{CMA}_{3}$, and (e) DAPI fluorochrome staining of metaphase I chromosomes. Arrowheads indicate the sex bivalent. $\mathrm{Bar}=5 \mu \mathrm{m}$. 


\section{C-banding and fluorochrome staining}

The analysis using C-banding technique allowed the identification of small constitutive heterochromatic blocks located in the centromeric region of all chromosomes (figure 1,c). The base-specific $\left(\mathrm{CMA}_{3}\right.$ and DAPI) fluorochromes staining did not reveal positive blocks indicating that the $\mathrm{CH}$ in this species is not enriched with AT or GC base pairs (figure 1, $\mathrm{d} \& \mathrm{e})$.

\section{Silver nitrate staining and FISH}

The silver nitrate staining detected an amorphous region corresponding to nucleolar remnants in the sex bivalent neo-XY (figure 2,a), and marked the heterochromatic regions of chromosomes. However, it did not stain the sex chromosomes in advanced meiotic stages; indicating the absence of argirophilic proteins in the configuration of the sexual bivalent (figure 2,b). The physical chromosomal localization of rRNA genes detected the presence of rDNA sites on the $\mathrm{X}$ and $\mathrm{Y}$ chromosomes. The site of rDNA in the $\mathrm{X}$ chromosome is larger than that observed in the $\mathrm{Y}$ (figure 2,c).

\section{Discussion}

The diploid number of $E$. caribaeus analysed specimens corroborates the previous description by Cabral-de-Mello et al. (2007). Although belonging to different geographically isolated populations, and despite the significant diploid number reduction to $2 n=8$, all specimens showed the same karyotype through the conventional staining. The genus Eurysternus is strictly neotropical, with 28 described species so far, and shows as dispersion centre the Brazilian forests and the Guiana region, extending up from Mexico to north Argentina, without record in the fauna of Chile and Uruguay (Halffter and Halffter 1976; Jessop 1985; Martinez 1988;
Vaz-de-Mello 2000). The absence of chromosome polymorphisms in E. caribaeus indicates that presumably its diploid number reduction occurred in one ancestral population, before the dispersion process of this species. The reduced chromosome number of E. caribaeus is probably the resultant of pericentric inversions followed by fusions (Cabralde-Mello et al. 2007), as observed in other species belonging to Scarabaeidae, for instance, Bubas bubalus $2 n=18$, Xy (Angus et al. 2007), Dichotomius geminatus $2 n=18, \mathrm{Xy}_{\mathrm{p}}$, (Cabral-de-Mello et al. 2008), Isocopris inhiata $2 n=18$, $\mathrm{Xy}_{\mathrm{p}}$ (Bione et al. 2005a), and Macraspis festiva $2 n=18$, $\mathrm{Xy}_{\mathrm{p}}$ (Bione et al. 2005b). In some Scarabaeidae species, reduction in the diploid number caused by fusion between autosomes and autosome-X has been observed. Fusions that involve the sex chromosomes are responsible for diploid number reduction and the origin of neo-XY sex mechanism. These rearrangements, in addition to fissions, chromosome losses and increase in the size of Y, are responsible for karyotype differentiation in Scarabaeidae during their evolution (Yadav and Pillai 1979; Yadav et al. 1979; Bione et al. 2005b; Macaisne et al. 2006; Cabral-de-Mello et al. 2007; Cabral-de-Mello et al. 2008; Angus et al. 2007; Dutrillaux et al. 2007).

Chromosome fusions have been observed in other groups of Coleoptera, insects and arthropods as a whole, and they are related to diploid number reduction and generation of neo-XY sex mechanism, as also observed in $E$. caribaeus. In Coleoptera, examples of diploid number reduction and/or neo-XY origin were observed in Elateridae, Conoderus stigmosus $(2 n=16$, neo-XY), Lampyridae, Bicellonycha lividipennis $(2 n=18$, neo-XY) and other families (Schneider et al. 2006; Dias et al. 2007). This pattern of chromosomal evolution in insects has also been seen in other orders, for e.g., Heteroptera (Bressa et al. 1999), Odonata (Mola and Papeschi 1994), and to arthropods in

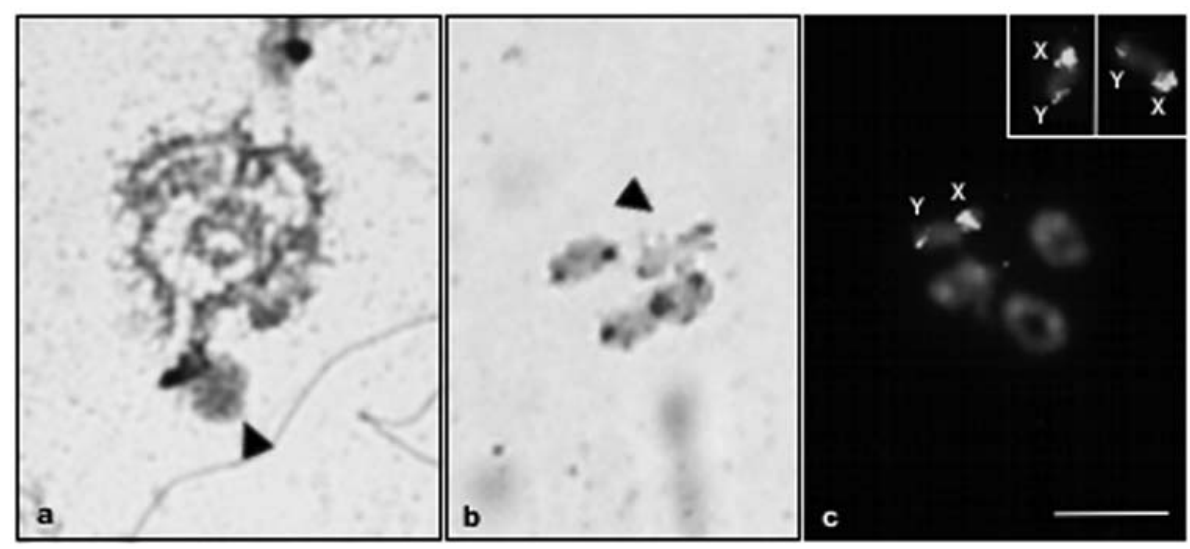

Figure 2. Meiotic chromosomes of E. caribaeus subjected to silver nitrate staining and fluorescence in situ hybridization (FISH). Silver nitrate staining of (a) zygotene, showing the NOR associated with the sex bivalent, (b) metaphase I, showing the affinity of the silver to the $\mathrm{CH}$ blocks, and (c) mapping of rRNA genes to metaphase I chromosomes, indicating the presence of 45S rDNA sites on the $\mathrm{X}$ and $\mathrm{Y}$ chromosomes (note the size difference of rDNA sites in the $\mathrm{X}$ and $\mathrm{Y}$ chromosomes (insert)). Arrowheads indicate the sex bivalent. Bar $=5 \mu \mathrm{m}$. 
general in spiders (Rezac et al. 2006) and pseudoscorpions (Stahlavsky and Kral 2004).

The C-banding pattern observed in E. caribaeus is quite common among Scarabaeidae representatives and also to Coleoptera as a whole (Moura et al. 2003; Colomba et al. 2004, 2006; Rozek et al. 2004; Wilson and Angus 2004, 2005, 2006; Bione et al. 2005b; Schneider et al. 2006). Meanwhile, particular cases of $\mathrm{CH}$ distribution have been reported in some Scarabaeidae; Cetonia aurata and Bubas bison have $\mathrm{CH}$ blocks located in the terminal region of eight autosomal bivalents, in addition to the pericentromeric blocks (Colomba et al. 1996, 2006; Dutrillaux et al. 2006). In some species of Scarabaeidae, such as Diabroctis mimas and Isocopris inhiata, the occurrence of diphasic chromosomes that present one heterochromatic and another euchromatic arm has been described (Bione et al. 2005a). In addition to these patterns, there are still some species with almost total heterochromatic chromosomes or with $\mathrm{CH}$ absence. In Lygirus ebenus, Geniates borelli and Pelidnota pallidipennis, the $\mathrm{X}$ chromosome is almost totally heterochromatic, while the Y do not show CH blocks (Bione et al. 2005b).

The $\mathrm{CH}$ neutrality observed using base-specific fluorochromes $\mathrm{CMA}_{3}$ and DAPI in E. caribaeus is presumably related to the presence of AT and GC base pairs intercalated repetitions or to the minute size of $\mathrm{CH}$ blocks, which disables the visualization of positive marks (Colomba et al. 1996, 2000, 2006; Moura et al. 2003; Bione et al. 2005a,b). The presence of neutral blocks has been observed in two other species, Phyllophaga capillata, with eight bivalents having neutral blocks, and Strategus surinamensis hirtus, that has one small autosomal pair that shows absence of fluorochrome marks (Moura et al. 2003; Bione et al. 2005b). However, Scarabaeidae has shown heterogeneity regarding $\mathrm{CH}$ base pair composition. In addition to species with neutral $\mathrm{CH}$ blocks, species with AT-rich blocks have also been recorded, such as Bubas bison and Pelidnota pallidipennis, as well as species with GC-rich blocks, such as Geniates borelli and Gymnopleurus sturmi, and also species with AT-rich and GCrich blocks as observed in Phyllophaga (Phytalus) vestita (Colomba et al. 1996, 2000, 2006; Moura et al. 2003; Bione et al. 2005b). The patterns of distribution and quality of $\mathrm{CH}$ indicate that the repetitive DNA in this group has distinct patterns of differentiation by accumulation of mutation over the evolutionary diversification of this lineage. This mechanism is common in some groups of insects and results from gene conversion, unequal crossing over, slippage replication and transposition (Charlesworth et al. 1994; Dover 2002; Palomeque and Lorite 2008).

In $E$. caribaeus, the nucleolar organizer region is located in the sex bivalent, differing from the most common pattern detected in Coleoptera, that is the location of NORs in one autosomal pair (Moura et al. 2003; Almeida et al. 2006; Schneider et al. 2007b). The observation of rDNA sites on the $\mathrm{X}$ and $\mathrm{Y}$ chromosomes of E. caribaeus using the FISH technique suggests the occurrence of fusion be- tween an autosomal pair, carrying rDNA sequences, and the sex chromosomes, with the fusion also being responsible for the diploid number reduction in this species. Using conventional staining, Cabral-de-Mello et al. (2007) proposed only the occurrence of autosome fusions, but in this work the differential cytogenetic techniques permitted the observation of autosome-X fusions. The presence of NORs in both sex chromosomes is uncommon to Scarabaeidae and Coleoptera as a whole. In Scarabaeidae only the species Jumnos ruckeri had NORs detected by silver nitrate in the $\mathrm{X}$ and $\mathrm{Y}$ chromosomes (Macaisne et al. 2006). Some other analysed species of Scarabaeidae presented NORs associated with the sex bivalent, but the rDNA sites are located only in the $\mathrm{X}$ chromosome, as observed in Phyllophaga (Phytalus) vestita, Lyogenys fuscus and Megasoma actaeon (Moura et al. 2003; Dutrillaux et al. 2007). Moreover, Scarabaeidae species with rDNA sites in a single autosomal bivalent have also been described, as Phyllophaga capillata and Isocopris inhiata (Moura et al. 2003; Bione et al. 2005a). There are yet other species with different patterns of rDNA cistrons location. In Bubas bison, these sites are present in eight chromosomes, while in Diabroctis mimas two autosomic pairs and the X chromosome have rDNA sites (Bione et al. 2005a; Colomba et al. 2006). This variability in the number and location of rDNA sites is probably caused by the transposition process of this DNA in the genome that is favoured by the chromocenter formation during the meiosis in this group. The differences in size of rDNA sites on the $\mathrm{X}$ and $\mathrm{Y}$ chromosomes in E. caribaeus is possibly the result of differential amplification of this sequence in the sex chromosomes, caused by several mechanisms of evolution of the repetitive DNA.

The absence of silver nitrate staining in the sex bivalent in metaphases I of E. caribaeus corroborates the presence of a sex mechanism distinct from the parachute, that remains strongly marked by the silver nitrate in some representatives of Scarabaeidae during different phases of meiosis, independent of whether or not the NORs are located in this bivalent (Virkki et al. 1991; Moura et al. 2003; Bione et al. 2005b). This phenomenon is related with the presence of argirophilic proteins in the lumen of the $\mathrm{Xy}_{\mathrm{p}}$. According to Virkki et al. $(1990,1991)$, these proteins are responsible for the 'adhesiveness' of these chromosomes acting in the maintenance of the parachute configuration and in the correct disjunction of this bivalent during cell divisions. The $\mathrm{CH}$ staining by silver nitrate observed in this work is probably related to the presence of argirophilic proteins in the molecular organization of the chromatin. This phenomenon has been frequently seen in Scarabaeidae species, as described in Lyogenys fuscus, Geniates borelli, Isocopris inhiata and Glyphoderus sterquilinus (Colomba et al. 1996; Moura et al. 2003; Bione et al. 2005a,b).

Although E. caribaeus has undergone diverse chromosome rearrangements that generated a significant diploid number reduction, the four populations studied here did not 
show polymorphisms for diploid number, sex mechanism and chromosome morphology. The fusion events are probably the main rearrangement responsible for the chromosome differentiation in this species, acting in diploid number reduction and in the translocation of rDNA sites to the sex chromosomes. This is the first time that a rDNA site is observed in the Y chromosome in Scarabaeidae family using FISH, a more reliable technique than silver nitrate staining that show affinity to the heterochromatic blocks and mark only the active NORs. Other species of Eurysternus need to be examined using differential cytogenetic techniques for the realization of a comparative analysis, which will elucidate the evolutionary mechanisms involved in the chromosome differentiation of this genus and family.

\section{Acknowledgements}

The authors are grateful to Conselho Nacional de Desenvolvimento Científico e Tecnológico (CNPq) and to Fundação de Amparo a Pesquisa do Estado de Pernambuco (FACEPE) (Process number 006/2003: PPP/MCT/CNPq/CT-INFRA/FACEPE, R. C. Moura); to $\mathrm{CNPq} / \mathrm{PIBIC} / \mathrm{UPE}$ scientific initiation scholarships of $\mathrm{A}$. $\mathrm{P}$. Arcanjo, to Fernando Silva for the taxonomic identification of the species, to Cristiane Costa and Sárah Oliveira for the individuals collected in Bolivia, and to Dr Cesar Martins for critically reading and commenting on a previous version of this manuscript.

\section{References}

Almeida M. C., Campaner C. and Cella D. M. 2006 Karyotype characterization, constitutive heterochromatin and nucleolus organizer regions of Paranaita opima (Coleoptera, Chrysomelidae, Alticinae). Genet. Mol. Biol. 29, 475-481.

Angus R. B., Wilson C. J. and Mann D. J. 2007 A chromosomal analysis of 15 species of Gymnopleurini, Scarabaeini and Coprini (Coleoptera: Scarabaeidae). Tijdschr. Entomol. 15, 201211.

Bione E. G., Camparoto M. L. and Simões Z. L. P. 2005a A study of the constitutive heterochomatin and nucleolus organizer regions of Isocopris inhiata and Diabroctis mimas (Coleoptera: Scarabaeidae, Scarabaeinae) using C-banding, $\mathrm{AgNO}_{3}$ staining and FISH techniques. Genet. Mol. Biol. 28, 111-116.

Bione E. G., Moura R. C., Carvalho R. and Souza M. J. 2005b Karyotype, C-and fluorescence banding pattern, NOR location and FISH study of five Scarabaeidae (Coleoptera) species. Genet. Mol. Biol. 28, 376-381.

Bressa M. J., Papeschi A. G., Mola L. M. and Larramendy M. L. 1999 Meiotic studies in Dysdercus Guérin Méneville 1831 (Heteroptera: Pyrrhocoridae). I. Neo-XY in Dysdercus albofasciatus Berg 1878, a new sex chromosome determining system in Heteroptera. Chrom. Res. 7, 503-508.

Cabral-de-Mello D. C., Silva F. A. B. and Moura R. C. 2007 Karyotype characterization of Eurysternus caribaeus: the smallest diploid number among Scarabaeidae (Coleoptera: Scarabaeoidea). Micron 38, 323-325.

Cabral-de-Mello D. C., Oliveira S. G., Ramos I. C. and Moura R. C. 2008 Karyotype differentiation patterns in species of the subfamily Scarabaeinae (Scarabaeidae: Coleoptera). Micron 39, 12431250.

Charlesworth B., Jarne P. and Assimacopoulos S. 1994 The distribution of transposable elements within and between chromo- somes in a population of Drosophila melanogaster. Genet. Res. 64, 183-197.

Colomba M. S., Monteresino E., Vitturi R. and Zunino Z. 1996 Characterization of mitotic chromosomes of the scarab beetles Glyphoderus sterquilinus (Westwood) and Bubas bison (L.) (Coleoptera: Scarabaeidae) using conventional and banding techniques. Biol. Zent. Bl. 115, 58-70.

Colomba M. S., Vitturi R. and Zunino M. 2000 Karyotype analyzes, banding, and fluorescent in situ hybridization in the Scarab beetle Gymnopleurus sturmi McLeady (Coleoptera, Scarabaeoidea, Scarabaeidae). J. Hered. 91, 260-264.

Colomba M. S., Vitturi R., Volpe N., Lannino A. and Zunino M. 2004 Karyotype, banding and rDNA FISH in the scarab beetle Anoplotrupes stercorosus (Coleoptera: Scarabaeoidea: Geotrupidae). Description and comparative analysis. Micron 35, 717720 .

Colomba M. S., Vitturi R., Libertini A., Gregorini A. and Zunino M. 2006 Heterochromatin of the scarab beetle, Bubas bison (Coleoptera: Scarabaeidae) II. Evidence for AT-rich compartmentalization and a high amount of rDNA copies. Micron 37, $47-51$.

Costa C. 2000 Estado de conocimiento de los Coleoptera Neotropicales. In Hacia un proyecto CYTED para el inventario y estimacion de la diversidad entomologica en iberoamerica: prIBES2000, monografias tercer milenio. (ed. F. Martin-Piera, J. J. Morrone and A. Melic), vol. 1, pp. 99-114. SEA, Zaragoza.

Dias C. M., Schneider M. C., Rosa S. P., Costa C. and Cella D. M. 2007 The first cytogenetic report of fireflies (Coleoptera, Lampyridae) from Brazilian fauna. Acta Zool. 88, 309-316.

Dover G. 2002 Molecular drive. Trends Genet. 18, 587-589.

Dutrillaux A. M., Moulin S. and Dutrillaux B. 2006 Use of meiotic pachytene stage of spermatocytes for karyotypic studies in insects. Chrom. Res. 14, 549-557.

Dutrillaux A. M., Xie H. and Dutrillaux B. 2007 High chromosomal polymorphism and heterozygosity in Cyclocephala tridentata from Guadalouoe: chromosome comparison with some other species of Dynastinae (Coleoptera: Scarabaeidae). Cytogenet. Genome Res. 119, 248-254.

Ferreira A. and Mesa A. 2007 Cytogenetics studies in thirteen Brazilian species of Phaneropterinae (Orthoptera: Tettigonioidea: Tettigoniidae): Main evolutive trends based on their karyological traits. Neotrop. Entomol. 36(4), 503-509.

Halffter G. and Halffter V. 1976 Notas sobre Eurysternus (Coleoptera, Scarabaeidae, Scarabaeinae). Folia Entomol. Mex. 37, 43-86.

Halffter G. and Favila M. E. 1993 The Scarabaeinae (Insecta: Coleoptera) an animal group for analysing, inventorying and monitoring biodiversity in tropical rainforest and modified landscapes. Biol. Int. 27, 15-21.

Hewitt G. M. 1979 Orthoptera: grasshoppers and crickets. Gerbruder Borntrager, Berlin.

Jessop L. 1985 An identification guide to Eurysternini dung beetles (Coleoptera, Scarabaeidae). J. Nat. Hist. 19, 1087-1111.

Karagyan G., Kuznetsova V. G. and Lachowska D. 2004 New cytogenetic data on Armenian buprestids (Coleoptera, Buprestidae) with a discussion of karyotype variation within the family. Folia Biol. 52, 151-158.

Macaisne N., Dutrillaux A. M. and Dutrillaux B. 2006 Meiotic behaviour of a new complex X-Y-autosome translocation and amplified heterocromatin in Jumnos ruckeri (Saunders) (Coleoptera, Scarabaeidae, Cetoniinae). Chrom. Res. 14, 909-918.

Machado V., Galián J., Araújo A. M. and Valente V. L. S. 2001 Cytogenetics of eight neotropical species of Chauliognathus Henzt, 1830: implications on the ancestral karyotype in Cantharidae (Coleoptera). Hereditas 134, 121-124. 
Martinez A. 1988 Notas sobre Eurysternus Dalman (Coleoptera, Scarabaeidae). Entomol. Bras. 12, 279-304.

Martins V. G. 1994 The chromosome of five species of Scarabaeidae (Polyphaga, Coleoptera). Naturallia 19, 89-96.

Mola L. M. and Papeschi A. G. 1994 Karyotype evolution in Aeshna (Aeshnidae, Odonata). Hereditas 121, 185-189.

Mola L. M., Papeschi A. G. and Taboada Carrillo 1999 Cytogenetics of seven species of dragonflies. Hereditas 131, 147-153.

Moscone E. A., Matzke M. A. and Matzke A. J. M. 1996 The use of combined FISH/GISH in conjunction with DAPI counterstaining to identify chromosomes containing transgene inserts in amphidiploid tobacco. Chromosoma 105, 231-236.

Moura R. C., Souza M. J., Melo N. F. and Lira-Neto A. C. 2003 Karyotypic characterization of representatives from Melolonthinae (Coleoptera: Scarabaeidae): Karyotypic analysis, banding and fluorescent in situ hybridization (FISH). Hereditas 138, 200206.

Palomeque T. and Lorite P. 2008 Satellite DNA in insects: a review. Heredity 100, 564-573.

Poggio M. G., Bressa M. J. and Papeschi A. G. 2007 Karyotype evolution in Reduviidae (Insecta: Heteroptera) with special reference to Stenopodainae and Harpactorinae. Comp. Cytogen. 1, $159-168$.

Rezac M., Král J., Musilová J. and Pekár S. 2006 Unusual karyotype diversity in the European spiders of the genus Atypus (Araneae: Atypidae). Hereditas 143, 123-129.

Rozek M., Lachowska D., Petitpierre E. and Holecová M. 2004 Cbands on chromosomes of 32 beetles species (Coleoptera: Elateridae, Cantharidae, Oedemeridae, Cerambycidae, Anthicidae, Chrysomelidae, Attelabidae and Curculionidae). Hereditas 140, 161-170.

Rufas J. S., Giménez-Abian J., Suja J. A. and Garcia de la Vega C. 1987 Chromosome organization in meiosis revealed by light microscope analysis of silver-stained cores. Genome 29, 706-712.

Schneider M. C., Almeida M. C., Rosa S. P., Costa C. and Cella D. M. 2006 Evolutionary chromosomal differentiation among four species of Conoderus Eschscholtz, 1829 (Coleoptera, Elateridae, Agrypninae, Conoderini) detected by standard staining, Cbanding, silver nitrate impregnation, and CMA3/DA/DAPI staining. Genetica 128, 333-346.

Schneider M. C., Rosa S. P., Almeida M. C., Costa C. and Cella D. M. 2007a Strategies of karyotype differentiation in Elateridae (Coleoptera, Polyphaga). Micron 38, 590-598.
Schneider M. C., Rosa S. P., Almeida M. C., Costa C. and Cella D. M. 2007b Chromosomal similarities and differences among four neotropical Elateridae (Conoderini and Pyrophorini) and other related species, with comments on the NOR patterns in Coleoptera. J. Zool. Syst. Evol. Res. 45, 308-316.

Schweizer D. 1976 Reverse fluorescent chromosome banding with chromomycin and DAPI. Chromosoma 58, 307-324.

Stahlavsky F. and Kral J. 2004 Karyotype analysis and achiasmatic meiosis in pseudoscorpions of the family Chthoniidae (Arachnida: Pseudoscorpiones). Hereditas 140, 49-60.

Smith S. G. and Virkki N. 1978 Coleoptera. In Animal cytogenetics (ed. B. John), pp. 366 Borntraeger, Berlin.

Sumner A. T. 1972 A simple technique for demonstrating centromeric heterocromatin. Exp. Cell. Res. 75, 304-306.

Vaz-de-Mello F. Z. 2000 Estado de conhecimento dos Scarabaeidae s. str. (Coleoptera: Scarabaeoidea) do Brasil. In Hacia un proyecto CYTED para el inventario y estimacion de la diversidad entomologica en iberoamérica prIBES-2000 monografias tercer milenio, (ed. F. Martin- Piera, J. J. Morrone and A. Melic), vol. 1 pp. 183-195. SEA, Zaragoza.

Virkki N., Mazzella C. and Denton A. 1990 Staining of substances adjacent to the $\mathrm{Xy}_{\mathrm{p}}$ sex bivalent of some weevils (Coleoptera: Curculionidae). J. Agric. Univ. Puerto Rico 74, 405-418.

Virkki N., Mazzella C. and Denton A. 1991 Silver staining of the coleopteran $\mathrm{Xy}_{\mathrm{p}}$ sex bivalent. Cytobios 67, 45-63.

Wilson C. J. and Angus R. B. 2004 A chromosomal analysis of ten European species of Aphodius Illiger, subgenera Acrossus Mulsant, Nimbus Muldant and Rey and Chilothorax Motschulsky (Coleoptera: Aphodiidae). Koleopterol. Rundsch. 74, 367-374.

Wilson C. J. and Angus R. B. 2005 A chromosomal analysis of 21 species of Oniticellini and Onthophagini (Coleoptera: Scarabaeidae). Tijdschr. Entomol. 148, 63-76.

Wilson C. J. and Angus R. B. 2006 A chromosomal analysis of eight species of Aphodius Illiger subgenera Agiolinus Schmidt, Agrilinus Mulsant and Rey and Planolinus Mulsant and Rey (Coleoptera: Aphodiidae). Proc. Russ. Entomol. Soc. 77, 28-33.

Yadav J. S. and Pillai R. K. 1979 Evolution of karyotypes and phylogenetic relationships in Scarabaeidae (Coleoptera). Zool. Anz. 202, 105-118.

Yadav J. S., Pillai R. K. and Karamjeet 1979 Chromosome numbers of Scarabaeidae (Polyphaga: Coleoptera). Coleopt. Bull. 33, 309-318. 